Physics International 1 (2): 110-114, 2010

ISSN 1948-9803

(C) 2010 Science Publications

\title{
Study of Electronic Properties of Metal-Insulator-Metal Structures for Fabrication of Cold Cathodes
}

\author{
${ }^{1}$ Hossein Ghaforyan and ${ }^{2}$ Majid Ebrahimzadeh \\ ${ }^{1}$ Department of Physics, Payame Noor University, \\ Tehran 193954697, I.R. of Iran \\ ${ }^{2}$ Arta Nano Fan Avar Pishro Co., Fars Science and Technology Park, \\ Arian Town, Shiraz, Iran
}

\begin{abstract}
Problem statement: The electrical properties of thin film structures consisting of metalinsulator-metal sandwiches are important in electronic devices. Approach: The electrical properties of thin film structures consisting of metal-insulator-metal sandwiches are investigated in this experimental work. Results: We are discussed of the electroformed metal-insulator-metal structures $\mathrm{Au}-\mathrm{MgF}_{2}-\mathrm{Au}$ and comparison with other $\mathrm{Au}-\mathrm{SiO} / \mathrm{CeF}_{3}-\mathrm{Au}, \mathrm{Cu}-\mathrm{CeF}_{3}-\mathrm{Cu}, \mathrm{Cu}-\mathrm{SiO}-\mathrm{Cu}, \mathrm{Au}-\mathrm{CeF}{ }_{3}-\mathrm{Au}$ specimens. There explains various properties including electron emission, electroluminescence, memory effects and, the differential negative resistance. The article is based upon experiments which identify the conduction process to be trap-controlled thermally activated tunneling between metal islands produced in the forming process. These devices undergo an electroforming process leading to resistivity decrease of several orders of magnitude along with a negative resistance region in their I-V characteristics. Conclusion/Recommendations: Experimental results show that $\mathrm{Cu}-\mathrm{SiO}-\mathrm{Cu}$ and $\mathrm{Au}-$ $\mathrm{MgF}_{2}-\mathrm{Au} \mathrm{Mg}$ specimens have high circulating current at room temperature and can be implication for the production of commercial electroformed devices such as cold cathode.
\end{abstract}

Key words: Thin film, cold cathodes, electroforming process, emission current

\section{INTRODUCTION}

The phenomenon of electroforming, or simply forming, of thin-film Metal-Insulator-Metal (MIM) structures has been known for half a century (Dearnaley et al., 1970), delineating the main facts and theories, gave an excellent review of the field and a more concise review is given by (Ghaforyan et al., 2008). The basic process and properties may be briefly stated. When a thin layer of insulator is sandwiched between two metal electrodes, placed in a vacuum and a voltage applied which is in excess of a certain critical voltage, the properties of the structure are changed permanently, reproducibly and in a profound manner. The device is then said to be 'formed' or 'electroformed'. Forming is possible with structures containing a wide variety of amorphous or microcrystalline insulators between a few tens and many hundreds of nanometres thick and a variety of metal electrodes, although the process occurs most readily when noble metals such as gold are used as the anode material. The forming voltage is not strongly dependent upon the dielectric or its thickness. The cathode material does not affect the forming process or subsequent properties. If the thickness of the insulating layer of a Metal-Insulator-Metal (MIM) device is in the correct range (100-10000 $\AA$ ) and the device is placed in a vacuum ( $<10-4$ mbar) at a high enough temperature (room temperature or above), it undergoes a process known as electroforming when a sufficiently high voltage (greater than the forming threshold voltage) is applied across it. Filaments are thought to be created between the metal electrodes which bridge the insulating gap and the device is said to be electroformed (or simply formed). Ghaforyan et al., has shown that, the transfer ratio is defined as the ratio of electron emission current $I_{e}$ to the circulating current $I_{c}$ for a given voltage applied across the sandwich. Results of such experiments indicated a strong attenuation of electrons in the top metal electrode and also provided evidence of inelastic interactions of the injected electrons in the top layer (Hickmott, 1962; Ilyas and Hogarth, 1983; Mordvintsev et al., 1998; Ray and Hogarth, 1985; Sharpe and Palmer, 1996; Silva et al., 2001; Simmons, 1963a; 1963b; Thurstans and Oxley, 2002; Reda, 2010; Iskandarani, 2010; Fen et al., 2011; Al-Saqer et al., 2010; Sadeghi et al., 2009).

(C) 2010 Hossein Ghaforyan and Majid Ebrahimzadeh. This open access article is distributed under a Creative Commons Attribution (CC-BY) 3.0 license which permits unrestricted use, distribution, and reproduction in any medium, provided the original work is properly credited. DOI: $10.3844 /$ pisp.2010.110.114 


\section{MATERIALS AND METHODS}

Specimen preparation: Thin insulator layers used in this experimental work were prepared by thermal evaporation of magnesium fluoride from a tantalum source in a balzers 510 coating unit. This unit consisted of evaporation facilities and a vacuum system capable of producing a vacuum of $10^{-6}$ torr and lower pressures of the order of $10^{-7}$ torr could be achieved with the addition of a liquid nitrogen trap. A radiant small heater was mounted in the vicinity of the substrates. Masks below the substrates could be rotated by an external rotary seal and a maximum of four different layers could be deposited. For deposition of $\mathrm{Au}$ and $\mathrm{Cu}$ layers, a tungsten crucible with $\mathrm{Al}_{2} \mathrm{O}_{3}$ layer was used to control the deposition rate and the thickness of the samples and two separate quartz crystal monitors were used. All samples used in this study were prepared by successive evaporation of the various layers without breaking the vacuum.

Measurements: All electrical measurements were carried out in a vacuum system capable of maintaining the samples at a pressure of about $5 \times 10^{-6}$ torr. The I-V characteristics were measured by traditional methods. To measure the temperature dependence of the I-V characteristics and also the electron emission from specimens, a small heater was used long with a metal cryostat which could be filled continuously with liquid nitrogen. The heater made of nichrome wire was placed between the cryostat which could be filed continuously with liquid nitrogen. It was so designed that it would not have an undesirable magnetic influence on the electron emission characteristics. A Kitley G10 electrometer was used for measurement of the emission currents with the accuracy of $10^{-15} \mathrm{~A}$.

A constant power supply unit was used to feed the heater and by the judicious use of cryostat and heater the required temperatures could be obtained. Device temperatures were recorded from a copper constantan thermocouple to the surface of the substrate. Electron emissions into vacuum were collected at a copper anode $(2.5 \mathrm{~cm} \times 7.5 \mathrm{~cm} \times 0.1 \mathrm{~cm})$ placed at a distance $1.0 \mathrm{~cm}$ from the specimens anode was kept at a potential of 100 volt with respect to earth. As shown in Fig. 1 and 2 for one evaporation procedure, six specimens were prepared on each substrate.

Attenuation length measurements: Measurements of the relative numbers of electron emitted through the thin top layer as a function of layer thickness yield directly values of the hot electron attenuation length.

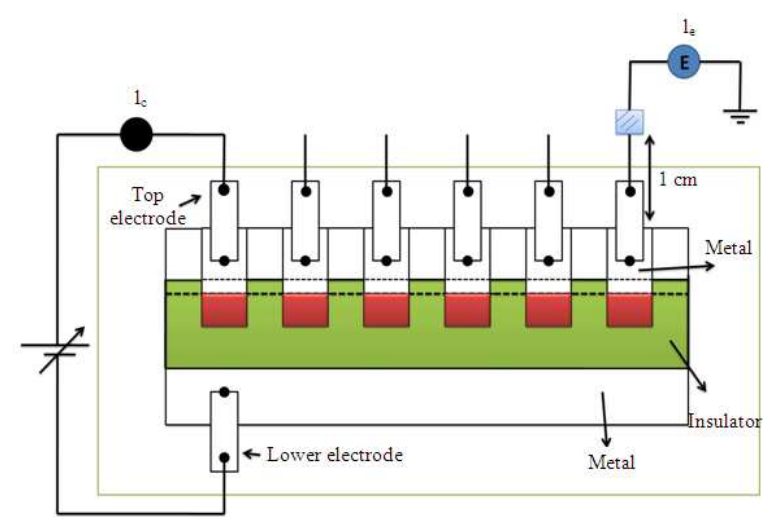

Fig. 1: Schematic view of the set-up implemented in this work

To determine this parameter experimentally, samples with constant top electrode thickness but with insulator layers of different thicknesses were prepared.

\section{RESULTS AND DISCUSSION}

The conductivity of the samples increases by several orders of magnitude when they are formed at room temperature in vacuum. As the voltage across the sample is increased, critical voltage is reached at which a sharp increase in current through the insulator layer occurs. On lowering the current through the sample, a pronounced negative resistance region occurs. On raising the voltage to successively higher values, the current voltage characteristic continues to show a negative resistance region for both increasing and decreasing voltages. Currents through the $\mathrm{MgF}_{2}$ layer are noisy and highly erratic during the first time that a voltage range is covered. However, on successive tracings of a characteristic the currents are much less erratic. The electroforming process consists of cycling the voltage applied across the sandwich between 0 and 14 volts with top electrode positively biased. The voltage required for the forming increase with the insulator thickness and it was found possible to form sandwiches electrically in which the insulator thickness was $1.5 \mu \mathrm{m}$. The forming voltage increased with decreasing temperature. The voltage at which the maximum peak current occurs varied between 2 and 3 volts for diodes having different material $(\mathrm{Au}$ and $\mathrm{Cu}$ ) and seemed to increase only very slightly with the thickness of the insulator layer. 
Phy. Intl. 1 (2): 110-114, 2010

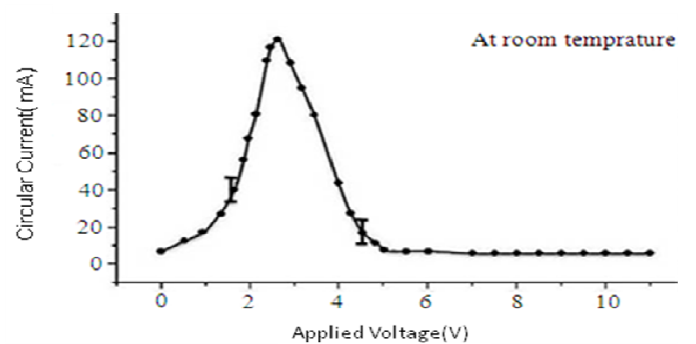

(a)

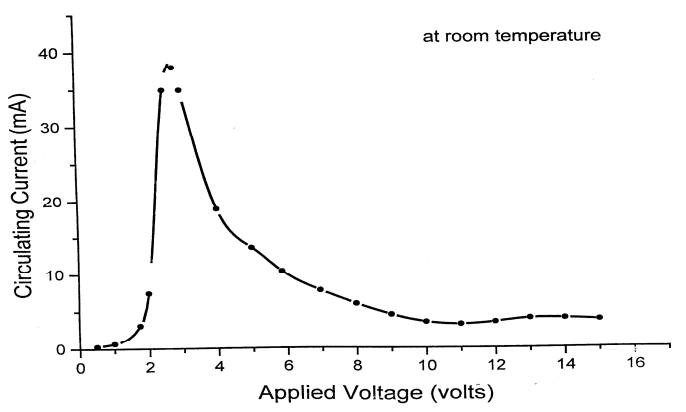

(b)

Fig. 2: Variations of circulating current versus the applied voltage for (a) $\mathrm{Au}-\mathrm{MgF}_{2}-\mathrm{Au}$ (b) $\mathrm{Cu}-$ $\mathrm{SiO}-\mathrm{Cu}$ samples

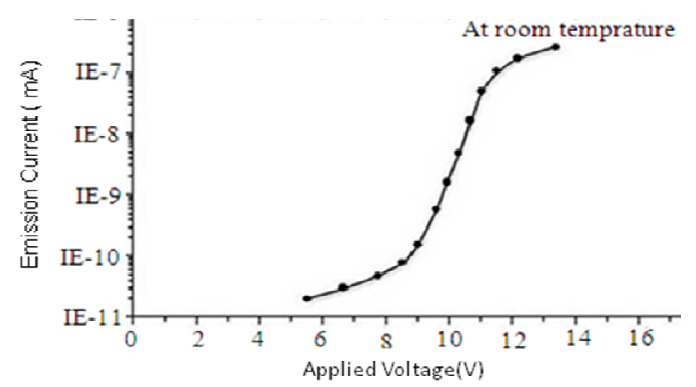

(a)

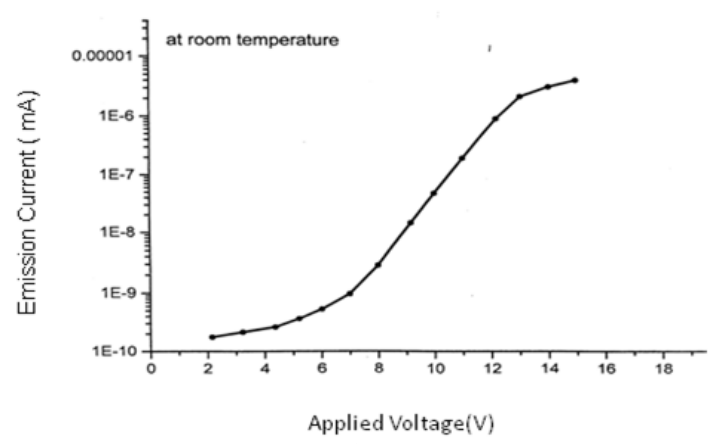

(b)

Fig. 3: Variations of emission current versus the applied voltage for a) $\mathrm{Au}-\mathrm{MgF}_{2}-\mathrm{Au}$ b) $\mathrm{Cu}-\mathrm{SiO}$ $\mathrm{Cu}$ samples

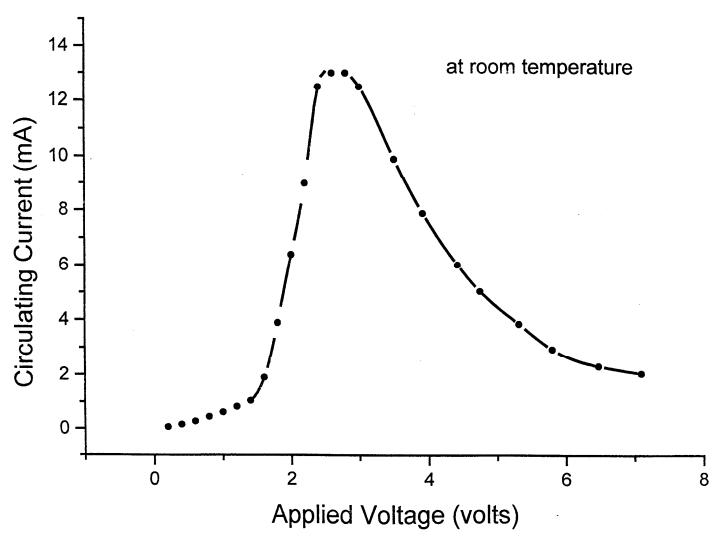

Fig. 4: Variations of circulating current versus the applied voltage at room temperatures (Au$\left.\mathrm{SiO} / \mathrm{CeF}_{3}-\mathrm{Au}\right)$

Temperature dependence of electrical characteristics: The electrical conductivity and the shape of the I-V characteristics were very sensitive function of temperature after the sandwiches had been electrically formed and significant conductivity had been established at room temperature (Gravano and Gould, 1992). As the temperature was lowered to $238 \mathrm{~K}$, the maximum circulating current and the general current level decreased gradually. Figure 4-6 shows the temperature dependence of various specimens' conductivity at room temperatures. Electron emission into a vacuum was observed as conductivity developed in the insulator and this emission current was also temperature dependent.

Attenuation length measurements: Figure 7 shows $\log \mathrm{a}=\log (\mathrm{Ie} / \mathrm{Ic})$ as a function of thickness of the $\mathrm{MgF} 2$ layers for different values of applied voltage. The slopes of the lines are striper for electrons emitted at lower applied voltages and indicate that the electrons of lower energy are more heavily attenuated than those of higher energies. Experimental evidence for the energy loss is provided by the fact that in general the transmission ration increases with increase of the applied voltage. Form the slopes of the graphs in Fig. 3 an attenuation length was derived for each value of applied voltage in the range $6-15$ volts. The values of $\lambda_{\mathrm{MgF} 2}$ are approximately constant $\left(1200 \mathrm{~A}^{\circ}\right)$ in the range $7-13$ volts and then rise with increasing voltages to a value of $\left(1800 \mathrm{~A}^{\circ}\right)$ at 15 volts applied. 


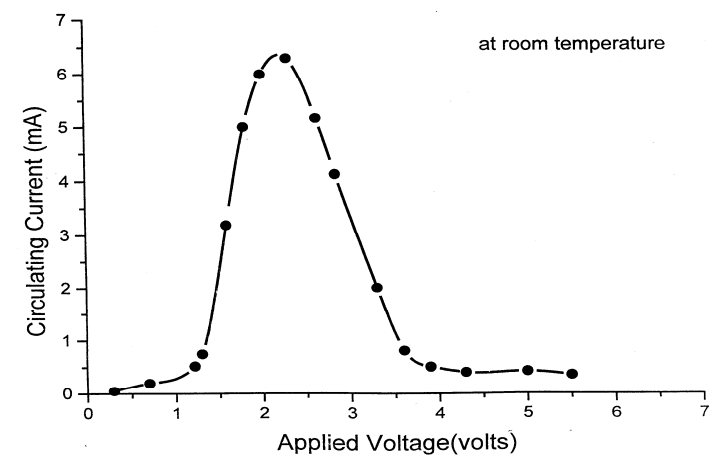

Fig. 5: Variations of circulating current versus the applied voltage at room temperatures $\left(\mathrm{Cu}-\mathrm{CeF}_{3}-\right.$ $\mathrm{Cu})$

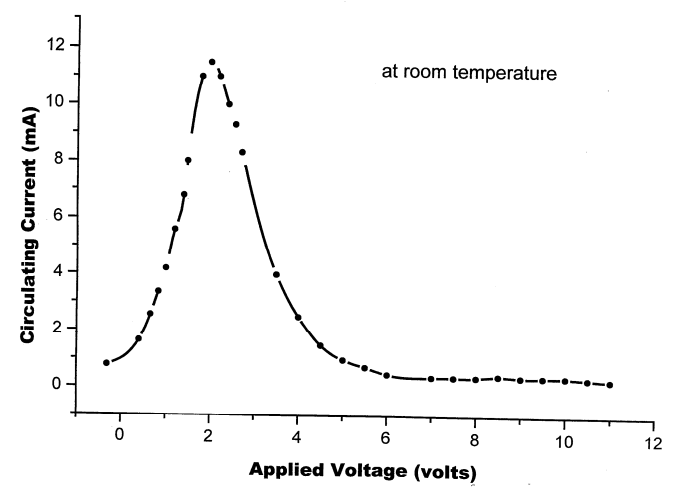

Fig. 6: Variations of circulating current versus the applied voltage at room temperatures $\left(\mathrm{Au}-\mathrm{CeF}_{3}-\right.$ $\mathrm{Au})$

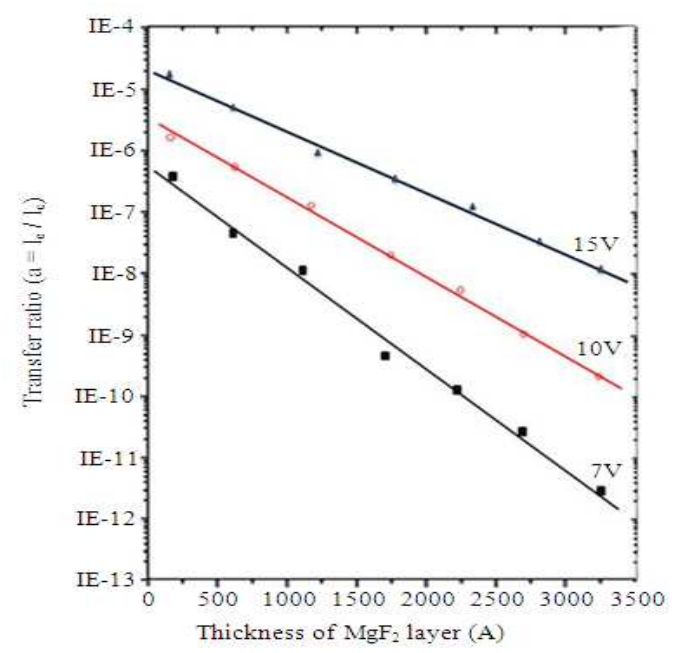

Fig. 7: Variations of transfer ratio versus $\left(\alpha=I_{e} / I_{c}\right)$ the thickness of $\mathrm{MgF}_{2}$ layers

\section{CONCLUSION}

Reasonably good electron emission properties are found and hot electron attenuation lengths are determined. The general electrical properties of $\mathrm{Au}$ $\mathrm{Mg}^{-1} \mathrm{~F}_{2} / \mathrm{Au}$ sandwich structure are similar to other metal-insulator-metal structure and point to the existence of a barrier layer near the cathode which can cause the free electrons to be accelerated to very high energies sufficient penetrate the reminder of the insulator, the top metal electrode and to be emitted into vacuum. The increase in circulating and emission currents at a given bias voltage observed at high temperature is expected since more thermal energy is available for transfer to the total energy of the electrons. The reduction density observed is of the order $1 \times 10^{-6}$ A. $\mathrm{cm}^{2}$. One of the more successful models of these phenomena is the filamentary model (Dearnaley et al., 1970), in which it is assumed that the electroforming process establishes a population of ohmic filaments within the insulating matrix, which span the metal contacts. The VCNR behavior results from the progressive cessation of conduction in individual filaments owing to Joule heating effects. Postulating plausible probability distributions of filament resistances that the I-V characteristics typical of those obtained in accordance with our experiment. The poly filamentary model of gold seems to indicate that a practical level of emission level of emission current has been achieved.

The circulating current initially increases with voltage faster than expected from Ohm's law, following typically either an $\mathrm{I}_{0} \mathrm{I}_{0} \operatorname{shin}\left(\mathrm{v} / \mathrm{v}_{0}\right)$ or an ${\mathrm{I} \alpha \mathrm{I}_{0}}_{0}\left(\mathrm{v} / \mathrm{v}_{0}\right)^{2}$ dependence, where $I$ is the current through the sample, $\mathrm{V}$ is the applied voltage and $\mathrm{I}_{0}$ and $\mathrm{V}_{0}$ are constants (Dearnaley et al., 1970). The conducting filaments were initially characterized in terms of a probability density distribution of filament resistances $\mathrm{P}(\mathrm{p})$ which was triangular, where $\mathrm{p}$ represents the filament resistance. Later work on the form of the function $\mathrm{P}(\mathrm{p})$ suggested that a parabolic distribution equally well described the experimental results, while it was also argued that a normal distribution of filament resistances was more fundamental (Ray and Hogarth, 1985) and that the earlier suggested distributions were merely approximations to this.

More recently the present authors have suggested that there is no a priori reason for suggesting that the filament resistances are normally distributed and that more basic attributes such as the filament radius (Gravano and Gould, 1992) or cross-al area may be normally distributed. Indeed, both of these assumptions 
have been shown to yield computed characteristics in accord with our experiment.

The transport and energy loss mechanism of hot electrons in metal films have been extensively studied both theoretically and experimentally. To study the energy loss mechanism in these samples, the transfer ratio a is measured as a function of the thickness of top or the insulator layers. The transfer or transmission ratio is defined as the ratio of electron emission current $I_{e}$ to the circulating current $I_{c}$ for a given voltage applied across the sandwich. Results of such experiments indicated a strong attenuation of electrons in the top metal and also provided evidence of inelastic interaction of the injected electrons in the top layer. Thurstans and Oxley (2002), described a new model is presented of the electroformed metal-insulator-metal structure which explains its various properties including electron emission, electroluminescence, memory effects and, for the first time, a complete account of the differential negative resistance (Silva et al., 2001). Measurements of the relative numbers of electron transmitted though the thin layer as a function of thickness of the layer; yield a direct measurement of the attention length. By extending the range of insulator thicknesses measured, it is possible to find out the values of attenuation length of hot electrons in the insulator.

\section{REFERENCES}

Al-Saqer, S.M., P. Weckler, J. Solie, M. Stone and A. Wayadande, 2010. Identification of pecan weevils through image processing. Am. J. Agric. Biol. Sci., 6: 69-79. DOI: 10.3844/ajabssp.2011.69.79

Dearnaley, G., A.M. Stoneham and D.V. Morgan, 1970. Electrical phenomena in amorphous oxide films. Rep. Prog. Phys., 33: 1129-1192. DOI: 10.1088/0034-4885/33/3/306

Fen, Y.W., W.M.M. Yunus, M.M. Moksin, M.A. Talib and N.A. Yusof, 2011. Optical properties of crosslinked chitosan thin film with glutaraldehyde using surface plasmon resonance technique. Am. J. Eng. Applied Sci., 4: 61-65. DOI: 10.3844/ajeassp.2011.61.65

Ghaforyan, H., H. Bidadi and M. Ebrahimzadeh, 2008. Electronic properties of $\mathrm{Au} / \mathrm{CeF}_{3} / \mathrm{Au}$ Structures at different temperatures. Inter. J. Pure Applied, Ph., 4: 113-118.

Gravano, S. and R.D. Gould, 1992. Calculations of the current-voltage characteristics of electroformed MIM structures, assuming a normal distribution of filamentary radii. Int. J. Elect., 73: 837-842.
Hickmott, T.W., 1962. Low-frequency negative resistance in thin anodic oxide films. J. Applied Phys., 33: 2669-2682. DOI: 10.1063/1.1702530

Ilyas, M. and C.A. Hogarth, 1983. The optical absorption edge of amorphous thin films of borosilicate glass. J. Mater. Sci. Lett., 2: 535-537. DOI: $10.1007 / \mathrm{BF} 00721476$

Iskandarani, M.Z., 2010. Mathematical modeling and characterization of thin film, narrow gap Sensor Array Units (SAU). Am. J. Applied Sci., 7: 12771284. DOI: 10.3844/ajassp.2010.1277.1284

Mordvintsev, V.M., S.E., Kudryavtsev and V.L. Levin, 1998. Aspects of the self-organization of carbonaceous conducting nanostructures during electroforming of a metal-insulator-metal open sandwich structure with a nanometer-size insulating gap. J. Techn. Phys., 43: 1350-1357. DOI: $10.1134 / 1.1259198$

Ray, A.K. and C.A. Hogarth, 1985. A note on the normal distribution of filamentary resistances in formed metal/insulator/metal devices. Thin Solid Films, 127: 69-76. DOI: 10.1016/00406090(85)90212-3

Reda, S.M., 2010. Photostability of ponceau 2R doped thin film sol-gel silica as luminescent solar collector. Energy Res. J., 1: 36-41. DOI: 10.3844/erjsp.2010.36.41

Sadeghi, M., M. Arbabi, A. Nikpey and G. Mardani, 2009. Aerobic biodegradation of per-treated methyl tert-butyl ether by ozonation in an up-flow-fixedbed reactor. Am. J. Environ. Sci., 5: 303-309. DOI: 10.3844/ajessp.2009.303.309

Sharpe, R.G. and R.E. Palmer, 1996. Evidence for field emission in electroformed metal-insulator-metal devices. Thin Solid Films, 288: 164-170. DOI: 10.1016/S0040-6090(96)08804-9

Silva, S.R.P. J.D. Carey, C.H. Poa, J.M. Shannon and 2001. Cold cathodes. Proceedings of the 1st International Symposium, Electrochemical Society, pp: 226-246. ISBN-10: 1566772958

Simmons, J.G., 1963a. Electric tunnel effect between dissimilar electrodes separated by a thin insulating film. J. Applied Phys., 34: 2581-2591. DOI: 10.1063/1.1729774

Simmons, J.G., 1963b. Generalized formula for the electric tunnel effect between similar electrodes separated by a thin insulating film. J. Applied, Ph., 34: 1793-1804. DOI: 10.1063/1.1702682

Thurstans, R.E. and D.P. Oxley, 2002. The electroformed metal-insulator-metal structure: A comprehensive model. J. Phys. D: Applied Phys., 35: 802-809. DOI: 10.1088/0022-3727/35/8/312 